\title{
A Case Study on the Effects of Glocal Second Language Setting on the Language Learning Motivation of Foreign Learners of Turkish
}

\author{
Ayşegül Takkaç Tulgar \\ Atatürk Univeristy \\ Turkey
}

\begin{abstract}
This case study examines the relationship between the glocal second language setting and the motivational levels of foreign learners of Turkish. Selected by purposeful sampling, the participants were 10 foreign learners of Turkish taking a year-long preparatory class in language education at AtaTömer. The content analysis of the data collected through six openended questions and semi-structured interviews showed that, being aware of the importance of motivation in language learning, the participants considered taking courses from native speaker teachers and having intercultural interaction with native speakers and classmates from different countries as motivating factors, while initial concerns for preserving cultural identity in the new community and some language-related difficulties were considered as demotivating factors in the glocal second language setting.
\end{abstract}

KEYWORDS: motivation, glocal motivation, Turkish language learning, Turkish as a second language, glocal context

\author{
Glocal Second Language Learning Setting \\ Literature Review \\ Methodology \\ Results \\ Discussion \\ Conclusion \\ References \\ Author Contact
}

The globalization of the world has offered world citizens many chances to have contact with other people from different countries through various opportunities like tourism, trade, and research. Education is also one of the essential common grounds connecting people with diverse linguistic and cultural backgrounds. An increasing number of learners are engaging themselves in international visits in which they can carry out some part or all of their undergraduate and/or graduate studies in a different country. To benefit from this expanding trend, learners put effort into learning the language of the host country, at least, at a certain level. As the number of international students desiring to receive higher education in Turkey has increased in the last decade, Turkish has also become one of the second languages receiving increasing attention. 
The number of people with the desire to learn Turkish is showing a remarkable increase with the expanding chances for international educational programs. Many people want to learn Turkish. These learners are provided language education in Turkey and abroad mainly through two official institutions: Yunus Emre Institute and TÖMER (Teaching Turkish Center). A great majority of universities in Turkey have TÖMERs, and they offer Turkish language education to international students who are planning to study at Turkish universities. These centers may be defined as glocal learning environments, as international students bring their cultural and social characteristics to the host country promoting global understanding while being exposed to the peculiar aspects of the local culture at the same time. The glocal atmosphere has direct or indirect influence on the motivational levels of international students in the language learning process.

With this perspective, this study aims to examine the relationship between the glocal second language learning environment and the motivational levels of foreign learners of Turkish. There has been comprehensive research on the notion of motivation in the process of language learning. However, there has not yet been a study examining motivation in the glocal second language learning context. Therefore, holding a "person-in-context" view of motivation (Ushioda, 2009, p. 219) in the glocal context, this study aims to investigate the motivational experiences of foreign learners of Turkish in the glocal second language setting. The study contributes to the understanding of the relation between motivation and the glocal language learning environment. In addition, it aims to present a perspective for the creation of comprehensive and cosmopolitan glocal second language learning settings in which fruitful language education and cultural sharing can be promoted.

\section{Glocal Second Language Learning Setting}

As a comparatively recent concept with a multidimensional nature, glocalization can be said as the reshaped and redefined version of globalization, placing emphasis on the interconnectedness of what is global and what is local (Robertson, 1995). With an all-embracing mentality, glocalization presents a new perspective that respects the unique existence of local cultures in the world.

Emphasizing the value of the local in the global framework, the notion of glocalization, which was first introduced in the context of agriculture in Japan (Robertson, 2012), has been integrated into such other fields as business and tourism (Khondker, 2013). The educational domain, language education in particular, is not an exception to the areas in which the effects of glocalization can be observed.

Considering the current cosmopolitan educational environments, one can easily observe that most of these contexts unite students from different linguistic, social, and cultural backgrounds. In such contexts, students not only engage themselves in the educational activities, but also naturally participate in newlyformed social contexts where they can be exposed to different cultures forming a 
global atmosphere, while presenting their own peculiarities and preserving the localities. Moreover, in such environments, learners develop new identities as the members of the new community involving different cultures and, therefore, can adopt multicultural identities as significant contributory members of the multicultural community.

Because of the increasing chances to host students from a number of different countries, higher education institutions can serve as places where multicultural communities, basically formed for educational purposes, can be maintained. Therefore, these institutions are becoming gradually glocalized. The effects of the glocal environment in higher education institutions can be observed particularly in contexts where language education is provided in preparatory classes. This study was conducted in such a context where the participants engaged themselves in learning Turkish in the second language learning environment in which they created a glocal atmosphere. Forming a new social and cultural community, they became the citizens of the new world they established contributing to world citizenship. In other words, the language learning environment provided an abstract motive for multicultural glocal citizenship. Therefore, studying this glocal context and presenting its social, cultural, and motivational dynamics will contribute to the understanding of glocal educational environments that create contexts with multicultural understanding and sensitivity. Such a research focus can help maintain educational environments holding glocal characteristics as houses hosting world citizens.

\section{Literature Review}

Motivation is a crucial factor in different areas of human life, and language education is not an exception (Dörnyei, 1998, 2001; Kormos, Kiddle, \& Csizér, 2011; Redondo \& Martin, 2015; Saito, Dewaele, \& Hanzawa, 2017; Song \& Kim, 2017; Ushioda, 2016). However, though the issue of motivation has received increasing attention in language studies, there is not an agreed-upon definition (Dörnyei, 1998). Pointing at the importance of maintaining the desire to learn a new language and having positive attitudes towards the target language for success in language learning, Gardner (1985) explains that motivation is "the combination of effort plus desire to achieve the goal of learning the language plus favorable attitude toward learning the language" (p. 10). Considering the process of language learning from the beginning to the end, Dörnyei (1998) defines language learning motivation as "the primary impetus to initiate learning the L2 and later the driving force to sustain the long and often tedious learning process" (p.117).

Regarding the driving effects of motivation on learning, research mainly refers to two sets of motivation types: intrinsic vs. extrinsic motivation and integrative vs. instrumental motivation. Intrinsic motivation can be described as the internal desire to learn new things while extrinsic motivation is the more external forces leading learners in their language studies (Dörnyei, 1994). Deci and Ryan 
(1985) explain that learners' having curiosity and enthusiasm for learning is a sign of their intrinsic motivation and add that this motivational source helps learners overcome external difficulties in the process. External motivation, on the other hand, is stimulated by outward factors which are related to the dynamics beyond individuals' inner mechanism and control. Brown (cited in Dörnyei, 1994) suggests that this type of motivation is generally triggered by the traditional learning environment in which grading becomes a source of motivation for learners.

In the context of language learning, motivation is also highly related to learners' perceptions of the target language, its culture, and its speakers. Regarding this connection, Gardner and Lambert (1972) proposed a socioeducational model introducing integrative and instrumental motivation. This model can be evaluated as the first model to take into account the motivational effects of social and cultural setting on learning (Maclntyre, MacKinnon, \& Cle'ment, 2009). In this model, integrative motivation, like internal motivation, is connected with learners' personal interest in and attitudes towards the target language and community. Integrative motivation is about the personal interest, desire, and persistence in learning (Horwitz, 1987). On the other hand, instrumental motivation, like external motivation, is more influenced by such outward factors as getting high marks from an exam or having a good job. Instrumental motivation refers more to the pragmatic gains that can result from the learning process (Locastro, 2001).

As the concept of motivation has been a popular topic of investigation in language studies, researchers have focused on the issue from many dimensions. Kim (2011), in a longitudinal study, aimed to investigate the language learning motivation of two Korean immigrants. The specific focus of the study was to evaluate the effects of perceived social context on the participants' motivation. The data collected through monthly semi-structured interviews for almost a year revealed the positive relationship between contextual perceptions and motivational levels. Additionally, it was suggested that it was actually not the context itself but the way it was perceived that influenced participants' motivation. Another longitudinal study was presented by Busse and Walter (2013), who worked with 94 first-year students enrolled in German degree courses. The purpose was to evaluate the motivational changes in a year-long learning process. The results of the questionnaires and interviews showed that temporal and contextual factors have negative/positive impact on learners' motivation over the course of learning. Like Busse and Walter (2013), Waninge, Bot, and Dörnyei (2014) also pointed at the influence of temporal and contextual factors on learners' motivation and concluded that context and the way learners conceived the context on an individual basis influenced their learning motivation in a dynamic system.

With an aim of better understanding the experiences of language learners in multilingual communities, Hamilton and Serrano (2015) administered a questionnaire to 90 non-native learners of Catalan to learn the effects of L2 (the language which a person is learning beside his native language in its authentic context) contact, participants' attitudes, and their motivation on their selfconceptions as language learners. The results showed that being in constant 
contact with the L2 culture and language positively influenced the participants' selfmotivation. With a similar stance, Harvey (2017) focused on examining the impact of direct exposure to the target language and constant contact with its native speakers on learning motivation. The researcher conducted interviews with a Russian learner of English over a year and concluded that learning the target language in its natural context increased the participant's motivation to learn the language better and to develop his new identity as a language learner.

A perusal of relevant literature reveals that studies conducted by Turkish researchers on language learning motivation can be grouped under two categories. The first one includes studies on motivation in foreign language learning. These studies have mainly focused on the concept of motivation in the process of learning English as a foreign language in Turkish context (Göktepe, 2014; Kızıltepe, 2000; Şentürk, 2015). The second category, examples of which follow, focuses on the concept of motivation in learning Turkish as a second language. Arslan and Gürsoy (2008) examined the effects of drama activities on the motivational levels of learners of Turkish as a second language. They analyzed the language materials and proposed different techniques to increase learner motivation like the integration of role plays, puppets, and pantomime. Karababa and Karagül (2013) aimed to identify the learning styles, language skills, topics, materials, and learning contexts that learners of Turkish need in the language learning process. Conducting a needs-analysis survey with 305 foreign learners, the researchers noted that the foreign learners of Turkish expected to cover topics related to Turkish culture presented through audio-visual materials. Pointing at the importance of the same aspect, Koçer (2013) underlined the fact that developing an effective curriculum to increase learner motivation in language learning is based on a comprehensive needs analysis. Stressing the need to understand the experiences and identify the problems in the process in order to increase learner motivation, Melanlıoğlu (2014) collected data through document analysis and semi-structured interviews. The results showed that listening was the most problematic, among basic language skills, decreasing learners' motivation. Kalfa (2015) focused on the qualifications that teachers of Turkish should have. The results of the survey completed by teachers of Turkish revealed that teachers are expected to hold a motivating attitude while teaching and maintaining a motivating learning environment. Highlighting the significance of students' perceptions of the learning context, Çetin, Bahar and Griffiths (2017) developed a questionnaire and gathered the opinions of 319 foreign learners of Turkish regarding local culture. Though not exposing major conclusions about language learning motivation, the results revealed that the participants had overall positive experiences and perceptions.

This literature review points to one foremost conclusion that motivation has been a concept attracting increasing attention in language education literature. Different aspects related to the motivational dynamics have been examined in both the national and international arena among which the effects of learning environment are also involved. There are two main points that can emerge from an analysis of the existing research. First, the evaluation shows that existing research has been conducted in foreign and second language learning contexts. 
The results mainly showed that the learning context, accompanied with the way the participants perceived the learning environment, had positive or negative effects on the motivational levels of the learners. However, Turkish as a second/foreign language still remains an area needing further investigation considering the increasing number of foreign learners learning Turkish as a second language in Turkey. The second point is that while the effects of the learning environment have been an issue of worldwide investigation, this still remains an area needing attention in learning contexts holding glocal characteristics.

Therefore, with an aim to introduce a different perspective to motivation studies, this study investigates the relationship between the glocal learning setting and language learning motivation of foreign learners of Turkish in Turkey. The examination of glocal learning environments that have recently been introduced into the field of language education can contribute to the understanding of both overall and particular characteristics of such learning contexts and their motivational effects in the language learning process. In this way, this study also presents the particulars of an existing phenomenon to language instructors and curriculum designers in this specific field helping them to better understand the unique aspects of their language education contexts and, hence, to design the materials and courses accordingly.

\section{Methodology}

This study adopted case study design to understand the motivational experiences of foreign learners of Turkish in the glocal second language learning setting. The rationale behind adopting case study is to approach the issue under investigation "within its real-life context" (Yin, 1984, p. 13). In this way, the researcher can reach in-depth understandings of participant views and experiences (Bogdan \& Biklen, 2007) in their natural setting (Creswell, 1998).

\section{Setting and Participants}

The study was carried out at AtaTömer, established to provide a year-long Turkish preparatory education to foreign students who come to Turkey for their undergraduate or graduate studies. The setting was a glocal second language learning context, composed of international students, students and teaching staff both from the host city and from the other cities of the host country, and local citizens of the host city. In this context, people from different nationalities met for educational purposes, creating a glocal atmosphere in which the locals could unite with the global through the existence of international students. In such a glocal language learning context, international students had the opportunity to introduce their culture while they were being exposed to the linguistic and cultural aspects of the target language in its authentic setting at the same time. 
Purposeful sampling was adopted for participant selection as these participants were thought to represent the group (Patton, 1990) of learners carrying out their language learning process in a glocal second language learning context. The participants were 10 foreign Turkish language learners receiving a year-long preparatory language education at AtaTömer. They came from Georgia (1), Russia (1), Mongolia (1), Kyrgyzstan (1), Iran (1), Tajikistan (1), Afghanistan (1) and Kazakhstan (3). These participants were provided scholarships by Presidency for Turks Abroad and Related Communities (YTB) founded by the Turkish government. They had received Turkish education in their country before coming to Turkey; therefore, they started at A2 level classes (the second level of language proficiency according to the Common European Framework of Reference, corresponding to the elementary level) at AtaTömer, Turkey. They received a yearlong preparatory education, which consisted of a 960-hour language program for 32 weeks.

\section{Data Collection Tools and Procedure}

The data were collected through open-ended questions and semi-structured interviews. These two instruments were designed to obtain separate data sets reflecting the issue from different angles, ensuring trustworthiness of the data. Before the main data collection process, permission from the related institution (AtaTömer) was obtained. In addition, informed consent from all the participants was taken to ensure the maintenance of the ethical procedures.

Regarding the first instrument, I, in the light of studies conducted on motivation in second language learning, formed six open-ended questions in Turkish. In order to increase the validity of the instrument, I consulted two field experts to check the clarity, understandability, and appropriateness of the items: one field expert on motivation in language education and the other on teaching Turkish as a foreign language. The open-ended questions given below were prepared in Turkish, as the participants were at C1 level of second language proficiency when the data were collected (the fifth level of language proficiency according to the Common European Framework of Reference, corresponding to the advanced level):

1. How did your motivation affect the process of your Turkish language learning?

2. How would you compare your motivation of Turkish language learning in your country with your learning motivation in Turkey?

3. What did learning Turkish from its native speakers affect your language learning motivation?

4. What factors generally increased or decreased your Turkish language learning motivation in the glocal environment?

The data for the open-ended questions were collected a month before the end of the preparatory class education when the participants could communicate accurately in the target language. Before answering the questions, all the 
participants signed a consent form showing their voluntary participation. They were also assured that their responses would be used only for the purposes of the academic research and confidentiality issues would be maintained.

For the second instrument, semi-structured interviews were conducted for data triangulation to ensure the trustworthiness of the findings. In order to establish unity between the two instruments, I formed a guide in light of the answers provided in the open-ended questions. Semi-structured interviews were conducted in the final week of the preparatory education when all the participants were about to receive their certificate of $\mathrm{C} 1$ level of language proficiency. Each interview lasted around 15 minutes; the participants were again asked to provide answers in Turkish.

After both data sets were collected, I translated the data into English and a native-speaker was asked to proofread the translations to confirm understandability and clarity of the findings. In addition, in order to obtain participant approval, the participants were shown the transcripts of their reflections and preliminary analysis. These steps were followed to ensure the trustworthiness of the findings.

\section{Data Analysis}

Content analysis was used for analyzing the data obtained from the participants. As there were two data sets, I followed a three-step process in data analysis. In the first step, the answers to the open-ended questions were analyzed. The transcripts of the participants were examined one by one, and recurring codes were identified for each participant. In the second step, I examined the transcripts of the semi-structured interviews using the same process, and similar recurring codes emerged in the second data set. These two separate data sets were analyzed in the same way in order to ensure trustworthiness of data analysis.

In the third step, after each data set was analyzed separately, a cross analysis was conducted to compare the results obtained from the data sets, increasing the trustworthiness of the analysis process as well. In addition, after completing the analysis process, I also asked a field expert to conduct data analysis for interrater reliability. The results of the second rater's analysis also pointed at similar recurring codes matching those I had identified. Similar procedures for analyzing two sets and conducting cross-set analysis and analysis by a second rater were all followed to ensure the trustworthiness of the analysis process.

\section{Results}

This section presents the results related with the motivational experiences of the participants in the process of learning Turkish in the glocal second language 
setting. The results are displayed under six sub-headings which were based on the open-ended questions including excerpts from participants' written answers to open-ended questions or oral answers during semi-structured interviews to illustrate their points of view more concretely. For a clear presentation, participant excerpts are referred to with some abbreviations. For example, OQ-P1 stands for an excerpt taken from the first participant's answer to the open-ended question and SI-P2 stands for the excerpt from the second participant in the semi-structured interview.

\section{The Effect of Motivation in Second Language Learning Process}

As adult learners, all the participants had already experienced the effects of motivation on learning. Specifically considering the language learning process, they were aware of the positive relationship between motivation and willingness to learn. They also stated that motivation influenced their readiness to learn the language and determined the amount of time spent on the language learning process, as maintained by a participant:

Motivation is an important factor in learning a new language. If you have motivation, you become willing to put effort in learning it. The process becomes much fruitful and you will spend less time to reach your goal. (OQP2-from Kazakhstan)

Seven participants also explained that motivation was a factor impacting the way they approached and shaped their learning. They noted that when they were motivated, they held positive attitudes towards the content to be learned, no matter how difficult it was, and searched for different ways to learn it. One participant, referring to the continuous and demanding nature of the language learning process, expressed that following different ways for successful language learning depends on proper motivation:

To me, motivation is almost the most important factor in language education because it is a long process requiring great and continuous effort. Without having enough motivation, a learner cannot keep up with the demands of language learning and have the willingness and the desire to fully accomplish language learning. (SI-P7-from Afghanistan)

Based on the participant remarks on the overall effects of motivation, it is clear that they appreciated motivation as a significant and effective dynamic in their learning process and they were aware of the power of motivation in their language learning process. They seemed to appreciate the driving force of the motivation in how they approach the process and how much effort they put in language learning. In other words, the comments revealed the connection between motivation and the level of the participants' willingness and the direction of their attitudes towards language learning. 


\section{Motivational Differences Between Learning Turkish at Home and in Turkey}

Since all the participants in this study had started learning Turkish in their own countries before coming to Turkey, they could make comparisons between their language learning experiences in foreign context and target setting. All the participants voiced their pleasure at receiving language education in its original context. They explained that learning Turkish in its target community was a great motivational factor for them because of the limitless chances of exposure to the target language. Pointing at the importance of the amount of exposure for language development, a participant referred to the positive contribution of multiple exposures to target forms on her language learning motivation by making a comparison between foreign context in her country and target context in Turkey:

I started to learn Turkish in Georgia. We were having Turkish classes with our teachers but the only way to hear the language was through the course materials. However, in Turkey, we can hear Turkish not just in the class. Wherever we go, there are native speakers of the language. So, this becomes a great motivational source for me. I know that language is not only in the class, it is everywhere. (SI-P3-from Georgia)

Another point of appreciation by the participants was about the ample chances to practice the language with its native speakers in the target setting. The participants maintained that learning Turkish in Turkey was much more effective, especially for the development of their communicative competence, because they could practice the language with its native speakers in different contexts. Available chances of exposure to and practice in the target language were the major missing facet in the participants' language education in their home countries. Calling attention to the motivational power of the available chances for exposure to and practice in the target language, a participant remarked:

When I was in Russia, I learned some basic things about Turkish language but since there were not many chances of using the language communicatively, what I learned could not go beyond memorization of some items. In Turkey, however, I can use the language whenever and wherever I want. I can practice the language in different contexts with different people who are all native speakers of Turkish. In this way, I can learn much more about the language beyond classroom instruction and this motivates me. (SI-P9-from Russia)

The participants' comparison of their language learning experiences in the foreign context and target context revealed that they favored learning the language in the target context as it offered them ample chances of exposure to the authentic forms of the target language and opportunities to practice it with its native speakers in different settings. The opportunity for language exposure and practice seems an essential factor motivating the participants in learning Turkish in Turkey. To put it 
in a different way, the availability of input and chances for output motivated the participants.

\section{The Effect of Language Learning from Native Speakers on Motivation}

All the participants verbalized their positive experiences in learning the language from its native speaker teachers. They explained that they could benefit from the native teachers more than the teachers in their home countries because the native speaker teachers were naturally much more knowledgeable about the target language and they could teach them its peculiar features and practical pragmatic usages as well as its general characteristics:

I think learning the language from its native speaker teachers is a great advantage. Of course, the non-native teachers in my home country helped me a lot to learn Turkish but I can now better observe the difference. Native speaker teachers have the natural talent of the language and whenever I have questions, they can provide me with more satisfying answers not only about the linguistic but also about the pragmatic usages of the language. (SI-P10-from Iran)

An additional aspect in the participants' comments was connected with the instructional capabilities and teaching approaches of the native teachers. Since they were native speakers of the target language, the teachers were considered more professional and friendly, by more than half of the participants, with respect to the content they were teaching and their way of instruction, as reflected in the statement below:

I have experienced learning Turkish first from non-native teachers and then from native teachers. So, I have observed the difference between them. I can say that native teachers teach more effectively than non-native teachers. Since it is their language, native teachers don't have difficulty in using, teaching and sharing it. (OQ-P4-from Tajikistan)

Instructors are one of the most essential and effective members in the language education process. Therefore, their having vast knowledge of the target language and teaching it effectively is significant for language learners. Since the language instructors in this case were native speakers of Turkish, they were considered successful representatives of the language by most of the participants. The instructors' success in teaching the language and having intuitive knowledge of it can be considered as a trait increasing the participants' motivation.

\section{Factors Increasing or Decreasing Motivation for Language Learning}

When asked about the effects of different factors influencing their motivational levels, all the participants referred to three factors: two initially 
demotivating factors and one about the expectations of the participants to share their cultural peculiarities. The first factor of common reference was their initial concern regarding the possible negative consequences of the learning experience on their personal and cultural identities. Especially in the first few weeks in the host country, the participants felt the unease that living in a foreign country over a certain period and being constantly exposed to that culture might negatively influence their national and cultural identities. However, as they had chances of contact with local people as well as their friends from different countries, they realized that the social and cultural diversities contributed to their understanding of and respect for differences, as a participant explained:

In the first two weeks, I hesitated to communicate with my classmates from different nationalities and with the local people outside AtaTömer because I didn't know their culture and they didn't know mine. I had two other friends from my country and we were generally spending our time together. But, the more our lecturers encouraged us to communicate with individuals outside the class, the better we started to know each other. Now, I believe that we can live with other people from different cultures without losing our own cultural identity. It is certainly motivating to share things, contribute to one another and develop global understanding and respect while still keeping your peculiarities. (OQ-P5-from Kazakhstan)

The second initial demotivator for language learning was the difficulty of communicating with the local people. Even if they had completed the A1 level before coming to the host institution, the participants were having problems understanding even some basic words because of the accent of the local people. However, in time, they developed their linguistic and communicative knowledge in the target language and got used to the local dialect. A participant who experienced serious disappointment because of the initial difficulties expressed that she overcame it with the help of the native speakers of the language:

Before coming to Turkey, I thought that I would not, at least, have problems while shopping because I knew the basic words in Turkish. However, when I saw that I had problems even buying some simple things, I was really disappointed. But, all changed especially with the friendly attitudes of my teachers in the host institution and the hospitality of the local people motivating me to understand and use the language effectively. (SI-P1-from Mongolia)

The last factor was about the expectations of the participants to be able to introduce their social and cultural peculiarities to Turkish citizens besides being exposed to their culture. One of the participants expressed that they were truly motivated by the encouraging attitudes of the host institution towards supporting them and providing them with the necessary opportunities to present their cultures while learning the cultures of their friends as well as the local culture:

Since we were from different nationalities, we were very eager to introduce our cultures to our friends. I need to say we were very lucky because the host institution did its best to help us and provide things whenever we 
needed them. Their positive and helping approach was particularly motivating for us. Probably, we couldn't have such opportunities of cultural sharing in our own countries. (OQ-P10-from Iran)

The participants were learning Turkish in a second-language-learning context but the environment was totally new to them. Therefore, the novelty brought some concerns with it. The main concern to maintain their personal and cultural identities in the new learning community naturally influenced the motivational levels of the participants. However, since they developed their language knowledge and skills in time with the help of their language instructors and the local people, they felt more comfortable communicating and interacting with the people around. The sense of getting used to the language, its people, and its culture increased their motivation as expected.

\section{Having Classmates from Different Countries}

Considering the experience of having classmates coming from different parts of the world, all the participants, with one exception, expressed their positive views. They were content that the language learning experience in Turkey was a great chance not only for language development but also for the expansion of an understanding and appreciation of global perspectives. Since there were eight different nationalities in the group, the participants were exposed to different cultural aspects unique to each country. Learning Turkish in Turkey was obviously the common ground uniting these participants; therefore, the language was the tool for them to have an experience of sharing glocal atmosphere. The available chances created in the learning setting for sharing their cultures and learning many things from each other became a significant source of motivation for the participants in following their language studies more willingly and eagerly:

Almost each of my classmates is from a different country. This means there are many different cultures and languages in the class. At first, it seemed a bit scary to have friends from different nationalities. But, in time, I started to consider this as an advantage because I could learn many things about many different cultures. Turkish is the common language for us. We have realized that, through this language, we can share our cultures with each other. So, I think my friends and I are more motivated now to learn Turkish because it is the link between us and our cultures. (OQ-P6-from Kyrgyzstan)

On the other hand, one of the participants (P8-from Kazakhstan) explained that she did not consider having friends from different nationalities as a motivating factor especially in the initial stages. She explained that, mainly because of her being shy and partially because of her nationalistic viewpoint, she did not favor the activities of cultural sharing too much; instead, she felt more comfortable while communicating with friends from her own nationality:

I don't like interacting with friends from different cultures so much. There are two factors affecting this: my shyness and nationalistic view. Of course, 
I have respect towards other cultures but I still favor communicating with friends from my home country instead of friends from other nationalities. So, intercultural communication is not a motivating factor for me in learning Turkish in its natural setting. (SI-P8-from Kazakhstan)

Since almost all the participants were from different countries, they formed a new community involving linguistic, social, and cultural diversity. Therefore, they established a glocal community where they could share their local peculiarities while learning about those of others. The existence of this glocal environment was reported as an essential source of motivation for the participants in learning Turkish because it was the common means of communication among the members of the glocal community. Of course, the way they perceived the environment they participated in had an impact on how much they were motivated by the novelty and diversity in the learning atmosphere.

\section{Having Classmates from One's Own Country}

Favoring the contributions of diversity in their classroom, all the participants except P8 noted that they would not want to receive language education with all classmates from the same country. They referred to two main possible disadvantages of having classmates from their own countries, remembering their foreign language learning experience in their own countries. The first one, as nine of the participants stated, was that in their home countries they had friends from the same nationality and relied on their native language. The second disadvantage was that the setting in their home countries could not allow exposure to the cultural dimension of the target language they learned. The participants noted that the glocal second language setting provided them with a glocal cultural sharing atmosphere. However, P8 did not share this view; she again expressed that she felt more comfortable while interacting with friends from her own nationality. In addition, unlike the other participants, she did not think that using her native language would block her development in Turkish.

In conclusion, the comments of the participants revealed that linguistic, personal, social, and cultural factors were influential on the motivational levels of foreign learners of Turkish in their second language learning experience. The linguistic factors had to do with the competence in using the target language. The personal factors were related to preserving their national identity. The social and cultural factors were about the available chances for presenting their cultural peculiarities, learning about the national cultures of their classmates, and being exposed to the culture of the host country in a glocal second language learning setting. These points were all considered as factors increasing the motivational levels of the participants in the glocal second language learning environment. In such a setting, a glocal atmosphere was promoted for foreign learners of Turkish, enabling them to be exposed to the target language and its culture in its authentic context while having the chance to introduce their own culture to the local people and friends from other cultures. 


\section{Discussion}

The overall remarks of the participants revealed that they were aware of the significant role that motivation played in the process of target language learning. The participants maintained that motivation influenced their willingness and readiness to learn the language. It had an impact on the way they approached learning and shaped the process accordingly. This general perception of motivation in language learning held by the participants reminds us of the driving nature of this concept underlined by Dörnyei (1998) as the "primary impetus" (p. 117 ) initiating and maintaining learning. Since language learning requires great and constant effort, the participants in this research seemed to be conscious of the indispensable place and value of motivation in this process and therefore they, with the help of motivation, shaped their practices by designating the length and amount of effort they are supposed to put in language learning, as also suggested by Dörnyei (2001).

In the discussion of the effects of glocal learning contexts on the second language learner motivation, the learning setting can be observed to influence the motivational levels of the learners in two ways. The first factor pertains to the perceptions of learners regarding the learning environment, which was underlined as a powerful factor by Alzubaidi, Aldridge, and Khine (2016). As also proposed by Ushioda (2009), learners go through processes of meaning-making, and they construe their learning experiences in the light of their perceptions stemming from their experiences. The results of this study showed that the participants developed positive attitudes towards their glocal language learning environment. From a more holistic and individualistic analysis of learner motivation, this positive development may be said to have increased their motivation to learn the target language. Considering the source of motivation for the participants in this study, it can be stated that they had both integrative motivation, since they were interested in the Turkish language and its culture, and instrumental motivation, as they were provided scholarship by the Turkish government. It seemed possible that the amount of integrative motivation for the participants in this research gradually increased when they started to have more contact with the citizens of the target culture and with their friends coming from different countries. This result was in parallel with the observations of Nikitina and Furuoka (2006) examining the motivational changes in learners of Russian towards the target language and culture. As in Nikitina and Furuoka's study, the participants in this study also experienced a positive change in their motivation in language learning as they had more contact with the culture and the language.

The second factor attracting attention in the glocal setting is connected with the unique characteristics of the language learning environment. The participants in this study expressed their pleasure at learning Turkish in its natural and authentic setting. As they all had already started to learn Turkish in their home countries before continuing their language education in Turkey, they could make 
comparisons between the two learning contexts with regard to language development. The participants drew attention to their experience that context was a factor affecting language learning, a conclusion also noted by the participants in some previous studies (Joe, Hiver, \& Al-Hoorie, 2017; Waninge et al., 2014). The results of this study showed that learning the target language in its original setting offered the participants more chances for exposure to and practice in the target language, which has also been observable in the results of previous studies (Bardovi-Harlig \& Dörnyei, 1998; Lee, 2016; Neddar, 2012; Roever, 2012; Schauer, 2006). The ample opportunities of exposure and practice offered by the second language learning setting can be said to have served as factors to enhance the participants' language skills and their cultural knowledge and thus increased their language learning motivation.

Taking classes from native speaker teachers was also referred to as one of the motivating factors by the participants. Since the native teachers had the natural capacity to use the target language, they were considered more effective than the non-native language teachers. In addition, as maintained by MacIntyre (2002), these teachers positively influenced the way the foreign learners perceived and approached the process of learning the target language in the host country. The motive driving the participants to learn the language better can be related to the positive attitudes they develop towards the target language and its culture with the help of the constructive attitudes of their native speaker teachers. Since perceptions or attitudes directly and indirectly impact the motivational levels of language learners (Kim, 2011), the participants in this study were motivated in language learning as observed in their positive attitudes towards the language and its culture through their interactions with the native speakers.

Besides having native speaker language teachers, the motivational level of the participants was also impacted by the glocal atmosphere. In this glocal atmosphere, the participants could introduce a global stance to the local people of the host institution and host city and could learn the local culture from them. By combining a global perspective formed by the foreign learners coming from different parts of the world and the local perspective introduced by the local citizens of the host country/city and the host institution, the Center offered its learners a learning environment that had an educationally, socially, and culturally glocal nature. The participants felt the motivation and desire to contribute further to the maintenance of the glocal culture in this socializing learning atmosphere. In addition, observing that they could hold their cultural peculiarities while interacting with other cultures, they affiliated themselves with the target language and its culture as well as the culture of their friends.

Having contact with friends with different linguistic, social, and cultural backgrounds was also a motivating factor for the participants in the process of developing a sense of intercultural appreciation. They enjoyed the chance of learning many new things about different cultures while sharing their own cultural peculiarities during classes or extra-curricular activities. Just as reported by Clarke and Hennig (2013) in their study, the participants in this study also experienced personal and social development that would not generally be possible in their 
home countries. Experiencing similar processes of adaptation to their new learning environment and new culture, the participants may have developed a sense of group-specific motivation, as proposed by Brown (1994), influencing their attitudes towards the target culture and their friends' cultures. The group dynamics developed through the desire for relatedness (Ortega, 2009) may have created a positive and pleasing learning and sharing atmosphere contributing to their global understanding.

This case study was intended to present a new perspective to research on language learning motivation centering on the concept of motivation in glocal second language learning setting. However, the limited number of participants and limited interview data, as each interview lasted for about 15 minutes, were the main limitations in securing richer and more in-depth data in this study. In addition, the participants had had some previous experience of learning Turkish in their home countries, which may have affected the way they approached the process of language learning. Future research can be conducted with participants without any experience of learning the target language in their native countries. Cross-analysis of the cases comparing the factors affecting motivation in foreign language learning contexts and second language learning contexts can also be explored.

\section{Conclusion}

This case study revealed that motivation in a glocal second language setting is an influential factor for language learning. In the second language learning context where this study was conducted, the participants could be exposed to the target language and its culture and have chances of interaction with classmates coming from various parts of the world and thus having different cultures. In this glocal environment, the participants had the chance to develop their sense of global understanding while still preserving their local peculiarities. This glocal sharing and socializing atmosphere naturally had positive effects on the motivational levels of the participants to improve their second language knowledge and skills.

In the light of the results of this study, the following options can be offered to increase the motivational levels of foreign learners in glocal settings:

- Foreign learners can be encouraged to communicate not only with their teachers but also with their classmates in the target language. Since the target language is expected to be the common language, this process can bear fruitful results for the improvement of learning.

- The institution can organize events where foreign learners can be exposed to the local culture and can introduce their cultures. Learners can take part in groups introducing local culture so that they may communicate with local people during the preliminary stages of production and thus may grasp the interrelation between language and culture instead of just seeing the final presentation. 
- Foreign learners can be offered chances to present their cultural heritages using the target language. In this way, they may improve their target language through activities in a glocal atmosphere created by the host institution.

- Foreign learners can be encouraged to have more contact with students studying in other departments at the university. In this way, the possible negative effects of social or educational superiority between the interlocutors can be eliminated. Since they all are students going through similar educational experiences, foreign learners may feel more comfortable while interacting with the native students as well as other students from different countries. This process may decrease their anxiety and increase their motivation to develop their language knowledge and skills.

- Campus workers and local people can be informed about the importance of having positive interactions with foreign learners. They should be enlightened that their behaviors can have positive or negative influence on the motivation of foreign learners.

Finally, it should be kept in mind that cultural aspects peculiar to local spaces contribute to the formation of a global culture while glocal culture is formed by individuals coming from different parts of the world for various purposes and sharing life in a local space. In an era in which practices of learning languages in second language learning contexts are becoming more and more common, offering language learners many chances to follow their studies in these glocal environments should hold priority to ensure the provision of ample chances of intercultural sharing and the maintenance of high levels of learner motivation.

\section{References}

Alzubaidi, E. Aldridge, J., \& Khine, M. (2016). Learning English as a second language at the university level in Jordan: Motivation, self-regulation and learning environment perceptions. Learning Environment Research, 19, 133-152. doi: 10.1007/s10984-014-9169-7

Arslan, M., \& Gürsoy, A. (2008). Establishing motivation in teaching Turkish as a second language through role playing and dramatic activities. Ege Journal of Education, 9(2), 109-127.

Bardovi-Harlig, K., \& Dörnyei, Z. (1998). Do language learners recognize pragmatic violations? Pragmatic vs. grammatical awareness in instructed L2 learning. TESOL Quarterly, 32, 233-259.

Bogdan, R. C., \& Biklen, S. K. (2007). Qualitative research for education: An introduction to theory and methods (5th ed.). Boston: Pearson Education, Inc.

Brown, H. D. (1994). Teaching by principles. Englewood Cliffs, NJ: Prentice Hall. 
Busse, V., \& Walter, C. (2013). Foreign language learning motivation in higher education: A longitudinal study of motivational changes and their causes. The Modern Language Journal, 97(2), 435-456. doi: 10.1111/j.15404781.2013.12004.x

Clarke, M., \& Hennig, B. (2013). Motivation as ethical self-formation. Educational Philosophy and Theory, 45, 77-90. doi: 10.1080/ 00131857.2012. 715386

Creswell, J. W. (1998). Qualitative inquiry and research design: Choosing among five traditions. Thousand Oaks, CA: Sage.

Çetin, Y., Bahar., M. \& Griffiths, C. (2017). International students' views on local culture: Turkish experience. Journal of International Studies, 7(3), 467-485.

Deci, E. \& Ryan, R. (1985). Intrinsic and extrinsic motivations: Classic definitions and new directions. Contemporary Educational Sociology, 25, 54-67. doi:10.1006/ceps.1999.1020

Dörnyei, Z. (1994). Understanding L2 motivation: On with the challenge. The Modern Language Journal, 78(4), 515-523.

Dörnyei, Z. (1998). Motivation in second and foreign language learning. Language Teaching, 31, 117-135. doi:10.1017/S026144480001315X

Dörnyei, Z. (2001). Teaching and researching motivation. Harlow, UK: Longman Pearson: Harlow, UK.

Gardner, R. C. (1985). Social psychology and second language learning: The role of attitudes and motivation. London, England: Edward Arnold Publishers.

Gardner, R. C., \& Lambert, W. E. (1972). Attitudes and motivation in second language learning. Newbury House: Rowley, MA.

Göktepe, F. (2014). Attitudes and motivation of Turkish undergraduate EFL students towards learning English language. Studies in English Language Teaching, 2(3), 314-332.

Hamilton, C., \& Serrano, R. (2015). Contact, attitude and motivation in the learning of Catalan at advanced levels. International Journal of Multilingualism, 12(3), 241-258. doi: 10.1080/14790718.2014.986127

Harvey, L. (2017). Language learning motivation as ideological becoming. System, 65, 69-77. doi:10.1016/j.system.2016.12.009

Horwitz, E. (1987). Surveying student belief about language learning. London, United Kingdom: Prentice Hall.

Joe, H., Hiver, P., \& Al-Hoorie, A. (2017). Classroom social climate, selfdetermined motivation, willingness to communicate, and achievement: $A$ study of structural relationships in instructed second language settings. Learning and Individual Differences, 53, 133-144. doi: 10.1016/j.lindif.2016.11.005 
Kalfa, M. (2015). Subject field competency analysis of teachers of Turkish as a foreign language. Education and Science, 40, 241-253. doi: 10.10. 15390/EB.2015.3064

Karababa, C., \& Karagül, S. (2013). A needs analysis for learners of Turkish as a foreign language. Education and Science, 38(170), 361-371.

Khondker, H. (2013). Globalization, glocalization, or global studies: What's in a name? Globalizations, 10(4), 527-531. doi:10.1080/14747731.2013. 806747.

Kızıltepe, Z. (2000). Attitudes and motivation of Turkish EFL students towards second language learning. International Journal of Applied Linguistics, 129, 141-168. doi: 10.1075/itl.129-130.01kiz

Kim, T. (2011). Sociocultural dynamics of ESL Learning (de)motivation: An activity theory analysis of two adult Korean immigrants. Canadian Modern Language Review, 67(1), 91-122. doi: 10.3138/cmlr.67.1.091

Koçer, Ö. (2013). The first step in curriculum development: Needs and situation analysis in teaching Turkish as a foreign language. Education and Science, 38(169), 159-174.

Kormos, J., Kiddle T., \& Csizér, K. (2011). Systems of goals, attitudes, and selfrelated beliefs in second-language learning motivation. Applied Linguistics, 32(5), 495-516. doi:10.1093/applin/amr019

Lee, E. (2016). Advanced ESL students' prior EFL education and their perceptions of oral corrective feedback. Journal of International Students, 6(3), 798-816.

Locastro, V. (2001). Individual differences in second language acquisition: Attitudes, learner subjectivity and second language. System, 29(1), 69-89.

Maclntyre, P. D. (2002). Motivation, anxiety and emotion in second language acquisition. In Peter Robinson (Ed.), Individual differences and instructed language learning (pp. 45-68). Amsterdam, The Netherlands: John Benjamins Publishing Company.

Maclntyre, P. D., MacKinnon, S. P., \& Cle'ment, R. (2009). The baby, the bathwater, and the future of language learning motivation research. In $Z$. Dörnyei \& E. Ushioda (Eds.), Motivation, language identity and the L2 self (pp. 43-65). Clevedon, United Kingdom: Multilingual Matters.

Melanlıoğlu, D. (2014). Perceptions of foreigners about process of learning Turkish. Bartın University Journal of Faculty of Education, 3(2), 368-389. doi:10.14686/BUEFAD.201428189.

Neddar, B. (2012). Short notes on discourse, interlanguage pragmatics and EFL teaching: Where do we stand? Procedia-Social and Behavioral Sciences 46, 5687-5692. doi: 10.1016/j.sbspro.2012.06.498

Nikitina, L., \& Furuoka, F. (2006, November). Integrative motivation: How perceptions of the target language country influence students' motivational 
pattern. Paper presented at the Science and Art of Language In Teaching International Conference, Pulau Pinang, Malaysia.

Ortega, L. (2009). Understanding second language acquisition. London, United Kingdom: Hodder.

Patton, M. Q. (1990). Qualitative evaluation and research methods. Newbury Park, CA: Sage.

Redondo, R., \& Martin, J. (2015). Motivation: The road to successful learning. Profile, 17(2), 125-136. doi: 10.15446/profile.v17n2.50563

Robertson, R. (1995). Glocalization: Time-space and homogeneity-heterogeneity. In M. Featherstone, S. Lash, \& R. Robertson (Eds.). Global modernities (pp. 25-44). London, United Kingdom: Sage.

Robertson, R. (2012). Globalisation or glocalisation? The Journal of International Communication, 18(2), 191-208. doi: 10.1080/13216597.2012. 709925

Roever, C. (2012). What learners get for free: Learning of routine formulae in ESL and EFL environments. ELT Journal, 66(1), 10-21. doi:10.1093/elt/ccq090

Saito, K., Dewaele, J., \& Hanzawa, K. (2017). A longitudinal investigation of the relationship between motivation and late second language speech learning in classroom settings. Language and Speech, 1-19. doi: $10.1177 / 0023830916687793$

Schauer, G. (2006). Pragmatic awareness in ESL and EFL contexts: Contrast and development. Language Learning, 56, 269-318.

Song, B., \& Kim, T. (2017). The dynamics of demotivation and remotivation among Korean high school EFL students. System, 65, 90-103. doi:10.1016/j.system.2016.12.010

Şentürk, B. (2015). EFL Turkish university students' attitudes and motivation towards reading in English. Procedia-Social and Behavioral Sciences, 199, 704-712. doi: 10.1016/j.sbspro.2015.07.601

Ushioda, E. (2009). A person-in-context relational view of emergent motivation, self and identity. In Z. Dörnyei \& E. Ushioda (Eds.), Motivation, language identity and the L2 self (pp. 215-228). Bristol, United Kingdom: Multilingual Matters.

Ushioda, E. (2016). Language learning motivation through a small lens: A research agenda. Language Teaching, 49(4), 564-577. doi:10.1017/ S0261444816000173

Waninge, F., Bot, K., \& Dörnyei, Z. (2014). Motivational dynamics in language learning: Change, stability, and context. The Modern Language Journal, 98(3), 704-723. doi: 10.1111/j.1540-4781.2014.12118.x

Yin, R. K. (1984). Case study research: Design and methods. Beverly Hills, CA: Sage. 


\section{Author Contact}

Ayşegül Takkaç Tulgar, aysegultakkac@hotmail.com

Atatürk University, Turkey English Language Teaching Department, Kâzım Karabekir Faculty of Education, Erzurum/TURKEY 